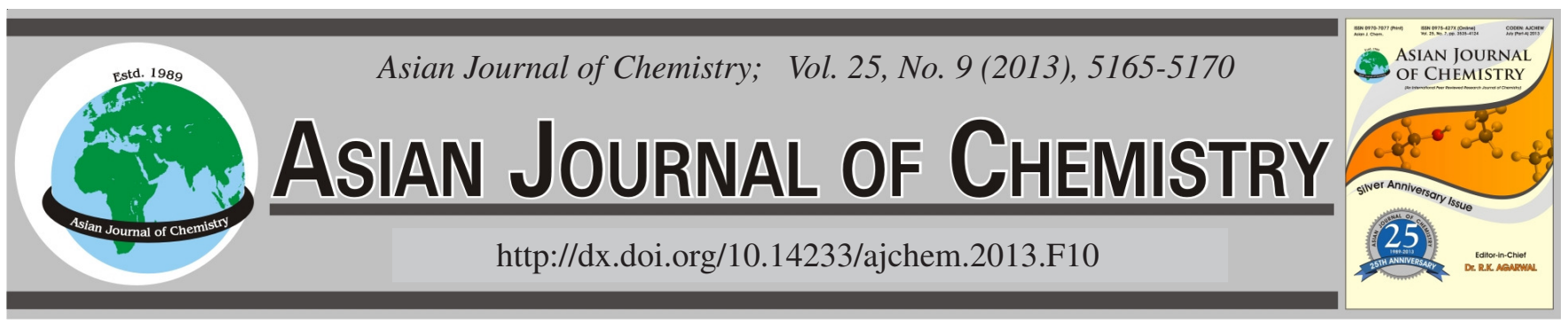

\title{
Effects of Aggregate Structure and Dimension of Carbon Nanotubes on the Mechanical, Electrical and Thermal Properties of Rubber Composites $\dagger$
}

\author{
Sung-Woo Kim*, Ho-Kyun Jeong, Yong-Gu Kang and Min-Hyeon Han
}

NEXEN Tire Corporation R\&D Center, Kyungnam 626-230, Republic of Korea

*Corresponding author: Fax: +82 55 3705366; Tel: +82 55 3705344; E-mail: ksw@ @exentire.co.kr

A tyre tread compound, showing good performance and high electrical conductivity, was prepared with a high silica loading and a low loading of multi-wall carbon nanotube in order not to sacrifice the original mechanical properties of the rubber compound. We fabricated styrene-butadiene rubber/natural rubber composites containing carbon black as a general filler and two types of multi-wall carbon nanotube with different structure and dimension, entangled carbon nanotube with short length $(<10 \mu \mathrm{m})$ and parallel-aligned carbon nanotube bundles with a long length $(<120 \mu \mathrm{m})$ as a specific filler. The incorporation of the aligned multi-wall carbon nanotube into the high silica rubber compound, even at low loading $(0.5 \mathrm{phr})$, improved the static dissipation to a level that could meet the requirements $\left(<10^{8} \Omega\right)$ for tyres without a measurable decrease in the physical and dynamic properties. The abrasion resistance was also enhanced considerably by $15 \%$ or more.

Key Words: Carbon nanotube, Static dissipation, Abrasion resistance.

\section{INTRODUCTION}

Since the discovery of carbon nanotube in $1991^{1}$, they have become one of the most active areas in the field of carbon nanotechnology owing their unique mechanical, electrical and thermal properties caused by the high aspect ratio, low diameter and metallic properties ${ }^{2-5}$.

Carbon nanotubes are essentially rolled up graphene sheets that are sealed to form hollow tubes. Single-wall carbon nanotubes (SWNT) are cylindrical tubes with a single outer wall with diameters of only 1-2 nm. Multi-wall carbon nanotubes (MWNT) have many layers of graphene wrapped around the core tube.

The use of multi-wall carbon nanotubes is advantageous in nanocomposites because, unlike single-wall carbon nanotube in which two-thirds are semi-conducting and only one-third are conducting, each individual multi-wall carbon nanotubes is conducting because it contains a large number of concentric single-wall carbon nanotubes.

Although the properties of multi-wall carbon nanotubes are excellent, they have not brought any remarkable improvements in the composite properties because of their poor dispersion due to the large surface area and weak interactions with polymer chains that causes large aggregates. As a result, the hysteresis and elongation as well as fatigue properties are decreased significantly ${ }^{6}$.
A few technical alternatives can be used to enhance the dispersion of multi-wall carbon nanotubes, such as ultrasonication, ball milling, heat treatment, acid treatment, in situ polymerization and latex treatments. On the other hand, it is extremely difficult to produce treated multi-wall carbon nanotubes on a mass production scale. Consequently, the broader use of multi-wall carbon nanotubess is still limited due to the high cost.

Therefore, carbon nanotube has been used mainly in high performance engineering resins and thermoplastics ${ }^{7-10}$. By incorporating carbon nanotubes into commercial high performance plastics and resins, conducting polymers can be prepared for demanding structural and aerospace applications with minimal impact on the mechanical performance. Applications include EMI shielding, static dissipation, electrostatic paint substrates and conductive coupling.

Recently, in the tyre industry, there has been increasing demand for highly silica-filled tyre tread compounds with better rolling resistance and wet grip than conventional carbon black treads due to the more stringent regulations over the world. On the other hand, high loading silica compounds show poor electrical conductivity which is essential for automobile manufacturers to meet the electrical resistance $\left(<10^{8} \Omega\right)$ for all original equipment tires. A low carbon nanotube loading can be used to impart static dissipation for tread compounds. 


\begin{tabular}{|c|c|c|c|}
\hline \multicolumn{4}{|c|}{$\begin{array}{l}\text { TABLE-1 } \\
\text { CHARACTERISTICS OF THE E-MWNT AND A-MWNT }\end{array}$} \\
\hline \multicolumn{2}{|c|}{ Material } & Entangled MWNT & Aligned MWNT \\
\hline \multirow[t]{2}{*}{ Diameter } & Individual CNT (nm) & $5 \sim 15 \mathrm{~nm}$ & $5 \sim 15 \mathrm{~nm}$ \\
\hline & CNT Bundle $(\mu \mathrm{m})$ & - & $6.5 \mu \mathrm{m}$ \\
\hline \multirow[t]{2}{*}{ Length } & Individual CNT $(\mu \mathrm{m})$ & $<10 \mu \mathrm{m}$ & $<120 \mu \mathrm{m}$, Average $80 \mu \mathrm{m}$ \\
\hline & CNT Bundle $(\mu \mathrm{m})$ & - & $<120 \mu \mathrm{m}$, Average $80 \mu \mathrm{m}$ \\
\hline BET Surface Area $\left(\mathrm{m}^{2} / \mathrm{g}\right)$ & 191 & & 285 \\
\hline \multirow{3}{*}{$\begin{array}{l}\text { Aggregate Structure } \\
\qquad(\text { SEM x } 1,000)\end{array}$} & Irregular Spheric & & ligned Type \\
\hline & & & \\
\hline & Random Entangle & \multicolumn{2}{|c|}{ Parallel Aligned Type } \\
\hline \multicolumn{4}{|l|}{$\begin{array}{l}\text { CNT Bundle Structure } \\
\text { (SEM over X5,000) }\end{array}$} \\
\hline
\end{tabular}

The benefit of such low levels of carbon nanotube addition for static dissipation is that the original mechanical properties of the composites can be maintained.

The types of ingredients and their concentration in rubber compounds affect the mechanical properties. Therefore, the requirements for the materials used in tyre production are quite stringent and qualification is a tedious process. Accordingly, it is advantageous to remain with that formulation once the formulation of a compound is qualified and fixed. Therefore, all mechanical, dynamic and hysteresis properties should be maintained even after adding additional materials, such as carbon nanotube, to the original formulation.

In this study, a tyre tread compound with good performance and high electrical conductivity was prepared using a high volume of silica. The multi-wall carbon nanotubes loading was kept low in order not to sacrifice the original mechanical properties of rubber compound.

Rubber composites with multi-wall carbon nanotube were fabricated and their mechanical, fatigue, electrical, thermal and viscoelastic properties were evaluated. Two types of multiwall carbon nanotube with different structures and dimensions were used, entangled carbon nanotube with a short length $(<10$ $\mu \mathrm{m})$ and vertically aligned carbon nanotube bundles with a long length $(<120 \mu \mathrm{m})$.

\section{EXPERIMENTAL}

The matrix materials were a styrene butadiene rubber with $27 \%$ bound styrene and a $59 \%$ vinyl content in a butadiene unit and natural rubber. The carbon-based nanofillers used were carbon black N339 (OCI Co. Ltd.), entangled multi-wall carbon nanotube (E-MWNT, Carbon Nanotech Co. Ltd.) and aligned multi-wall carbon nanotube (A-MWNT, Hanwha Nanotech Co. Ltd.). Silica (7000 Gr), bis-(triethoxysilylpropyl) tetrasulphide (TESPT), $N$-cyclohexylbenzo thiazole (CBS) and $N, N$ '-diphenylguanidine (DPG), zinc oxide ( $\mathrm{ZnO})$, stearic acid (S/A), sulfur and processing oil were all supplied by local manufacturers.

Characterization and measurement of properties: Scanning electron microscopy (SEM, JEOL JSM-6490LV) was used to observe the morphology of the pristine carbon nanomaterials. The curing characteristics were measured over a 30-min period at $160^{\circ} \mathrm{C}$ using a Oscillating disk rheometer (ODR) and the tensile properties were measured using a Universal Testing Machine (UTM, Instron Co., UK) at a crosshead speed of $300 \mathrm{~mm} / \mathrm{min}$.

The hardness was measured using shore A durometer (TECLOCK) and the fatigue properties of composites using Demattia flex cracking tester (DMFC, UESHIMA). The abrasion weight loss of the rubber composite was investigated using a William type abrasion tester.

The hysteresis properties of the nanocomposites were determined using a Heat Build-Up Flexometer (GABO) for heat generation and dynamic mechanic thermal spectroscopy (DMTS, Eplexor $500 \mathrm{~N}$ from GABO) for Tand at $0{ }^{\circ} \mathrm{C}$ and $60^{\circ} \mathrm{C}$.

The thermal conductivity was characterized using a thermal conductivity analyzer (QTM-500).

The electrical resistance of the rubber composites at room temperature was examined using a two-probe method on a high voltage insulation resistance tester (TERAOHM, MI2077). The two probes measured the electrical resistance at the interface between the probe tip and the nanocomposites.

\section{RESULTS AND DISCUSSION}

Table-1 summarizes the characteristics of the two kinds of multi-wall carbon nanotube. One is an entangled multiwall carbon nanotube (E-MWNT), which has randomly 
entangled carbon nanotube chains with a length less than $10 \mu \mathrm{m}$ and a BET surface area of $191 \mathrm{~m}^{2} / \mathrm{g}$. The aggregates had an irregular spherical structure. The other is an aligned multi-wall carbon nanotube (A-MWNT), which has parallelaligned carbon nanotube chains with lengths up to $120 \mu \mathrm{m}$ and a BET surface area of $285 \mathrm{~m}^{2} / \mathrm{g}$. The aggregates had a well aligned, long bundle structure.

Table-2 summarizes the formulations of the S-SBR/NR composites with multi-wall carbon nanotubes.

\begin{tabular}{|c|c|c|c|c|c|c|c|c|c|c|}
\hline \multirow{3}{*}{ Material } & \multicolumn{10}{|c|}{$\begin{array}{l}\text { ORMULATIONS OF THE SBR/NR COMPOSITES } \\
\text { WITH E-MWNT AND A-MWNT }\end{array}$} \\
\hline & \multicolumn{10}{|c|}{ Compound name (unit : phr) } \\
\hline & S1 & E1 & E2 & E3 & E4 & A1 & $\mathrm{A} 2$ & A3 & A4 & A5 \\
\hline S-SBR & 80 & 80 & 80 & 80 & 80 & 80 & 80 & 80 & 80 & 80 \\
\hline NR & 20 & 20 & 20 & 20 & 20 & 20 & 20 & 20 & 20 & 20 \\
\hline $\mathrm{C} / \mathrm{B}$ & 20 & 20 & 20 & 20 & 20 & 20 & 20 & 20 & 20 & 20 \\
\hline Silica & 40 & 40 & 40 & 40 & 40 & 40 & 40 & 40 & 40 & 40 \\
\hline E-MWNT & - & 1 & 3 & 5 & 7 & - & - & - & - & - \\
\hline A-MWNT & - & - & - & - & - & 0.5 & 1 & 3 & 5 & 7 \\
\hline TESPT & 3.2 & 3.2 & 3.2 & 3.2 & 3.2 & 3.2 & 3.2 & 3.2 & 3.2 & 3.2 \\
\hline Oil & 10 & 10 & 10 & 10 & 10 & 10 & 10 & 10 & 10 & 10 \\
\hline
\end{tabular}

All the composites consisted of solution styrene butadiene rubber and natural rubber as polymer matrices at a ratio of $80: 20$ and $20 \mathrm{phr}$ of carbon black and $40 \mathrm{phr}$ of silica as the conventional fillers of the tire tread compound. E-MWNT and A-MWNT were used as specific fillers at a ratio of $0.5,1,3,5$ and 7 phr.

Table-3 shows the change in Mooney viscosity by the incorporation of multi-wall carbon nanotubes. This dramatic increase was interpreted by the extremely high anisotropy in the shape of the multi-wall carbon nanotube chains and bundles. The A-MWNT composites showed a higher Mooney viscosity than E-MWNT due to the higher aspect ratio of the individual carbon nanotube chains and well aligned long bundle structures of carbon nanotube aggregates of A-MWNT.

Fig. 1 revealed a dramatic increase in modulus at low elongation. This corresponds to the Halpin and Tsai equation [eqn. (1) - (3)], which is useful for predicting of the composite properties with a non-spherical shape of composite materials and semi-empirical equations developed by curve fitting to consider the aspect ratio of reinforcement and dispersion. When the linear reinforcement of randomly oriented composites is assumed,

$$
\begin{aligned}
& \mathrm{E}_{\text {para }}=\mathrm{E}_{0}(1+2 \mathrm{f} \emptyset) /(1-\varnothing) \\
& \mathrm{E}_{\text {perp }}=\mathrm{E}_{0}(1+0.5 \varnothing) /(1-\varnothing) \\
& \mathrm{E}_{\text {rand }}=0.2 \times \mathrm{E}_{\text {para }}+0.8 \times \mathrm{E}_{\text {perp }}
\end{aligned}
$$

where para, perp and rand stands for parallel, perpendicular and random, respectively, $\mathrm{E}$ is the modulus of the composite, $\mathrm{E}_{0}$ is the modulus of pure composite, $\mathrm{f}$ is the aspect ratio of filler and $\varnothing$ is the volume fraction of the filler.

According to Halpin-Tsai theory higher aspect ratio of the filler causes a larger increase in the reinforcement of the modulus. Therefore, high aspect ratio of multi-wall carbon nanotubes can lead to orders of magnitude increases in the stiffening effect compared to spherical particles. The high aspect ratio, anisotropy and alignment of the A-MWNT in the matrix caused a more remarkable increase in the modulus than E-MWNT.

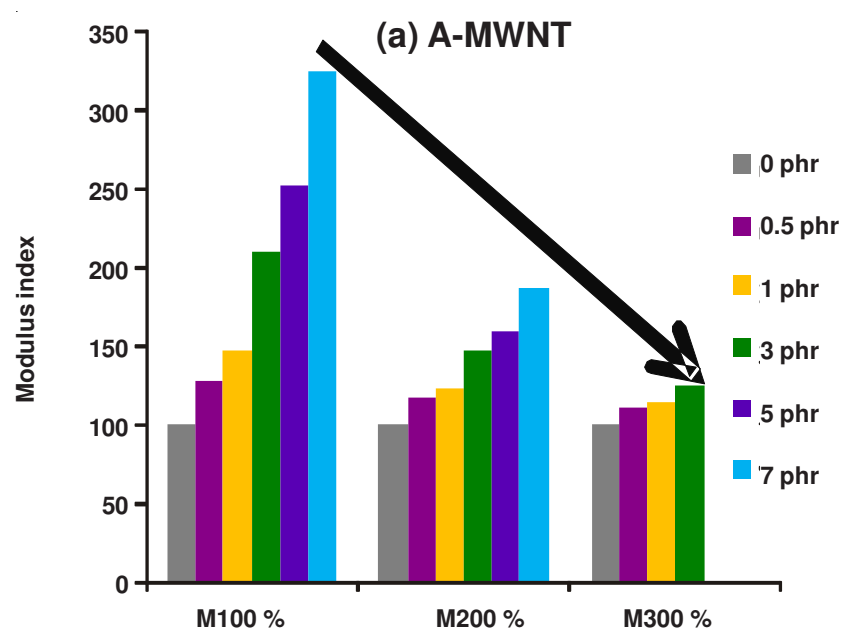

TABLE-3

\begin{tabular}{|c|c|c|c|c|c|c|c|c|c|c|}
\hline & \multicolumn{10}{|c|}{ Compound name } \\
\hline & $\mathrm{S} 1$ & E1 & E2 & E3 & $\mathrm{E} 4$ & A1 & A2 & A3 & A4 & A5 \\
\hline Mooney viscosity & 69 & 73 & 77 & 83 & 89 & 70 & 74 & 84 & 95 & 105 \\
\hline $100 \%$ Modulus (Mpa) & 3.1 & 3.5 & 4.3 & 4.6 & 5.2 & 4.0 & 4.6 & 6.6 & 7.9 & 10.2 \\
\hline 200 \% Modulus (Mpa) & 8.7 & 9.5 & 11.2 & 11.6 & 12.4 & 10.2 & 10.8 & 12.8 & 13.9 & 16.3 \\
\hline 300 \% Modulus (Mpa) & 15.0 & 16.8 & 17.7 & 17.9 & Failure & 16.6 & 17.2 & 18.8 & Failure & Failure \\
\hline Hardness & 65 & 67 & 70 & 71 & 73 & 69 & 72 & 75 & 79 & 81 \\
\hline Tensile strength (Mpa) & 20.0 & 19.9 & 19.0 & 18.4 & 17.9 & 18.9 & 18.9 & 19.2 & 18.2 & 19.0 \\
\hline $\mathrm{HBU}\left({ }^{\circ} \mathrm{C}\right)$ & 22.9 & 23.5 & 24.9 & 27.2 & 29.3 & 24.9 & 25.6 & 31.3 & 35.4 & 35.6 \\
\hline $\operatorname{Tan} \delta$ at $0^{\circ} \mathrm{C}$ (Wet Grip) & 1.122 & 1.065 & 0.998 & 0.983 & 0.957 & 1.111 & 0.960 & 0.836 & 0.665 & 0.591 \\
\hline $\operatorname{Tan} \delta$ at $60^{\circ} \mathrm{C}$ (rolling resistance) & 0.097 & 0.098 & 0.101 & 0.101 & 0.103 & 0.098 & 0.108 & 0.128 & 0.151 & 0.164 \\
\hline Abrasion weight loss $(\%)$ & 10.08 & 8.77 & 7.91 & 3.72 & 3.41 & 8.41 & 6.26 & 3.73 & 1.3 & 0.68 \\
\hline Crack growth 2,000 cycles $(\mathrm{cm})$ & 4.84 & 5.91 & 7.35 & 8.59 & 9.8 & 5.34 & 6.63 & 10.22 & 16.42 & 17.86 \\
\hline Crack growth 6,000 cycles $(\mathrm{cm})$ & 8.88 & 10.16 & 12.4 & 13.9 & 16.94 & 9.34 & 10.38 & 17.68 & 24.36 & Failure \\
\hline Crack growth 10,000 cycles $(\mathrm{cm})$ & 11.4 & 12.5 & 15.92 & 17.84 & 20.74 & 12.1 & 12.9 & 23.38 & Failure & Failure \\
\hline Electrical resistivity $\left(10^{8} \Omega\right)$ & 231000 & 224000 & 1650 & 5.8 & 0.4 & 17.3 & 0.224 & 0.033 & 0.01 & 0.009 \\
\hline
\end{tabular}

PHYSICAL, HYSTERETIC, THERMAL AND ELECTRICAL PROPERTIES OF THE NANOCOMPOSITES MIXED WITH E-MWNT AND A-MWNT 


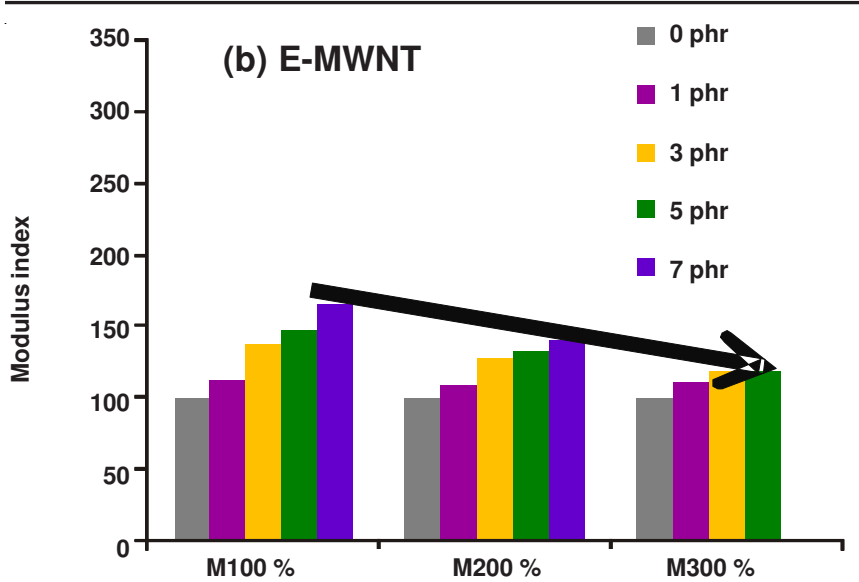

Fig. 1. Modulus index of the nanocomposites with (a) A-MWNT and (b) E-MWNT

The experimentally determined aspect ratio(f) of multiwall carbon nanotubes in the composites can be predicted using the Halpin-Tsai equation. The theoretical aspect ratio of A-MWNT was approximately 8,000 (L/D = $80 \mu \mathrm{m} / 0.01 \mu \mathrm{m})$ by the individual A-MWNT chains and approximately 12.3 $(\mathrm{L} / \mathrm{D}=80 \mu \mathrm{m} / 6.5 \mu \mathrm{m})$ by the A-MWNT bundles. For the E-MWNT, theoretical aspect ratio was approximately 1,000 (L/D $=10 \mu \mathrm{m} / 0.01 \mu \mathrm{m})$ by the individual A-MWNT chains. Table- 4 and Fig. 2 present the experimentally determined aspect ratio of the multi-wall carbon nanotubes. $E / E_{o}$ of the $100 \%$ modulus was calculated using the theoretical aspect ratio as mentioned above. In case of A-MWNT, the predicted $\mathrm{E} / \mathrm{E}_{\mathrm{o}}$ values calculated using an aspect ratio of 12.3 and 8,000 were significantly different from that calculated from the experimental values. On the other hand, the predicted $E / E_{o}$ values simulated by using $\mathrm{f} 250$ for A-MWNT and $\mathrm{f} 70$ for E-MWNT corresponded to the experimental E/E $\mathrm{E}_{\mathrm{o}}$ values. According to the Halpin-Tsai equation the actual diameter and length of the multi-wall carbon nanotube aggregates in the composites were recalculated using $\mathrm{f} 250$ for A-MWNT and $\mathrm{f}$ 70 for E-MWNT. The calculated dimensions of the multi-wall carbon nanotubes were $0.32 \mu \mathrm{m}$ in diameter and $80 \mu \mathrm{m}$ in length for A-MWNT and $0.14 \mu \mathrm{m}$ in diameter and $10 \mu \mathrm{m}$ in length for E-MWNT. This suggests that the multi-wall carbon nanotube are dispersed in the matrix not by individual chains but by divided bundles and aggregate units and also suggests that multi-wall carbon nanotubes in matrix have many curved and linked structures. The predicted $\mathrm{E} / \mathrm{E}_{\mathrm{o}}$ values at low multiwall carbon nanotube loadings are slightly lower than the experimental values because the Halpin-Tsai equation was developed for randomly oriented composites, whereas there could be many perfectly aligned structures of multi-wall carbon nanotubes at relatively low concentration.

Table-3 and Fig. 3 show the mechanical and hysteretic properties of the composites. The addition of multi-wall carbon nanotubes caused a dramatic increase in hardness due to the large surface area and high aspect ratio but a significant decrease in elongation, which corresponded to the increased stiffening properties. The multi-wall carbon nanotubes have a negligible effect on the tensile strength.

A-MWNT shows higher heat generation and has adverse effects on the wet grip and rolling resistance compared to
E-MWNT because A-MWNT has a strong likelihood of contact and friction under cyclic deformation. The concentration of A-MWNT over 1 phr reduces the elongation and hysteretic properties significantly, whereas a negligible negative effect on those properties is observed at low concentrations of $\sim 0.5$ phr or less.

TABLE-4

EXPERIMENTALLY DETERMINED ASPECT RATIOS OF (a) A-MWNT AND (b) E-MWNT

\begin{tabular}{|c|c|c|c|c|c|c|c|}
\hline (a) & A-MWN' & content (phr) & 0 & 1 & 3 & 5 & 7 \\
\hline \multirow{4}{*}{$\begin{array}{l}\mathrm{E} / \mathrm{E}_{\mathrm{o}} \\
(\mathrm{M}- \\
100)\end{array}$} & \multicolumn{2}{|c|}{ Experimental Value } & 1 & 1.47 & 2.09 & 2.53 & 3.25 \\
\hline & \multirow{3}{*}{$\begin{array}{l}\text { Predicted } \\
\text { value }\end{array}$} & $f: 12.3$ & 1 & 1.02 & 1.06 & 1.10 & 1.14 \\
\hline & & $f: 8000$ & 1 & 11.17 & 31.71 & 52.51 & 73.59 \\
\hline & & $f: \mathbf{2 5 0}$ & 1 & 1.32 & 1.97 & 2.63 & 3.29 \\
\hline (b) & \multicolumn{2}{|c|}{ E-MWNT Content (phr) } & 0 & 1 & 3 & 5 & 7 \\
\hline \multirow{3}{*}{$\begin{array}{l}E / E_{o} \\
(M- \\
100)\end{array}$} & \multicolumn{2}{|c|}{ Experimental Value } & 1 & 1.13 & 1.38 & 1.47 & 1.66 \\
\hline & Predicted & f : 1000 & 1 & 2.28 & 4.85 & 7.46 & 10.10 \\
\hline & value & f : 70 & 1 & 1.09 & 1.28 & 1.47 & 1.67 \\
\hline
\end{tabular}
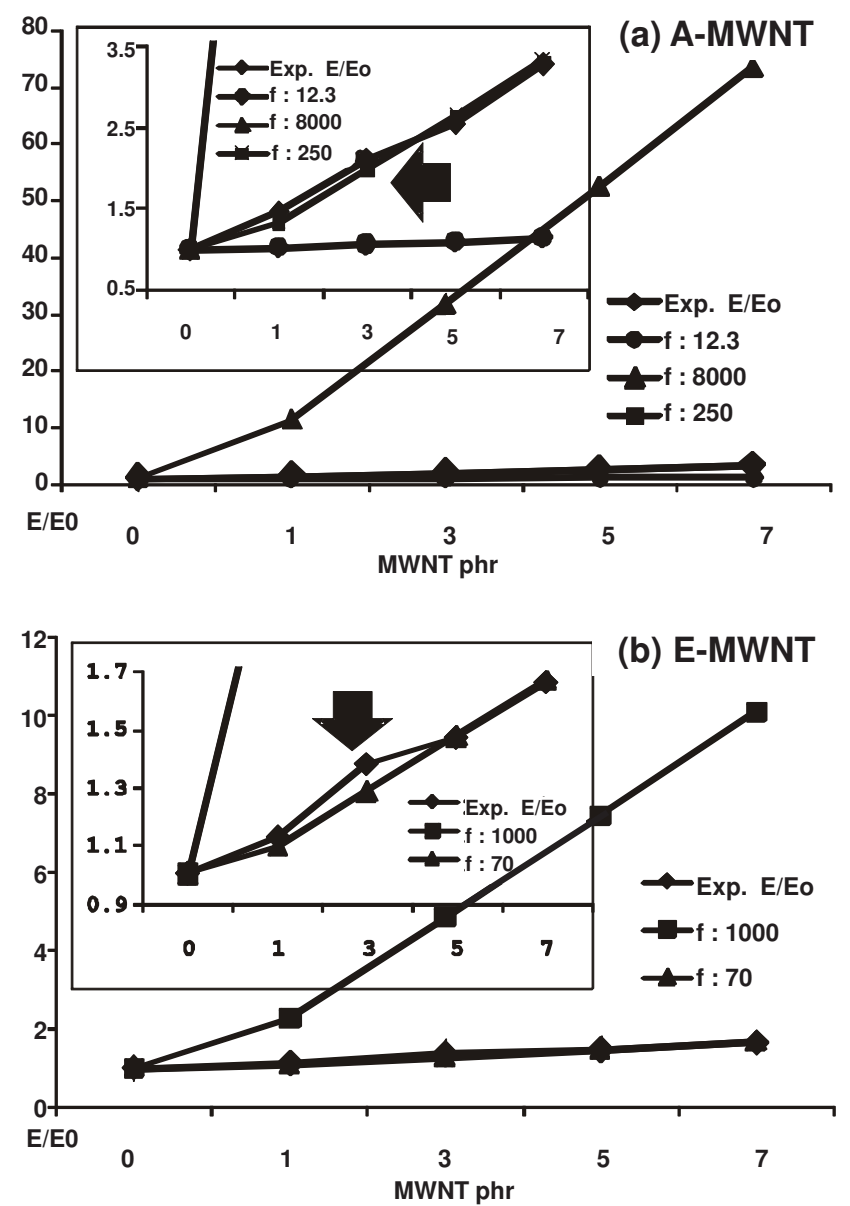

Fig. 2. Experimentally determined aspect ratios of (a) A-MWNT and (b) E-MWNT

Table-3 and Fig. 4 present the abrasion and fatigue properties. By incorporating A-MWNT into the rubber composites, the abrasion property increased dramatically whereas the fatigue property decreased exponentially. Even a $0.5 \mathrm{phr}$ loading of A-MWNT produced a $17 \%$ increase in abrasion resistance with almost no adverse effect on crack growth.

Fig. 5 shows that the thermal and electrical conductivity of the A-MWNT composites were enhanced remarkably compared to the E-MWNT composites and the composite 

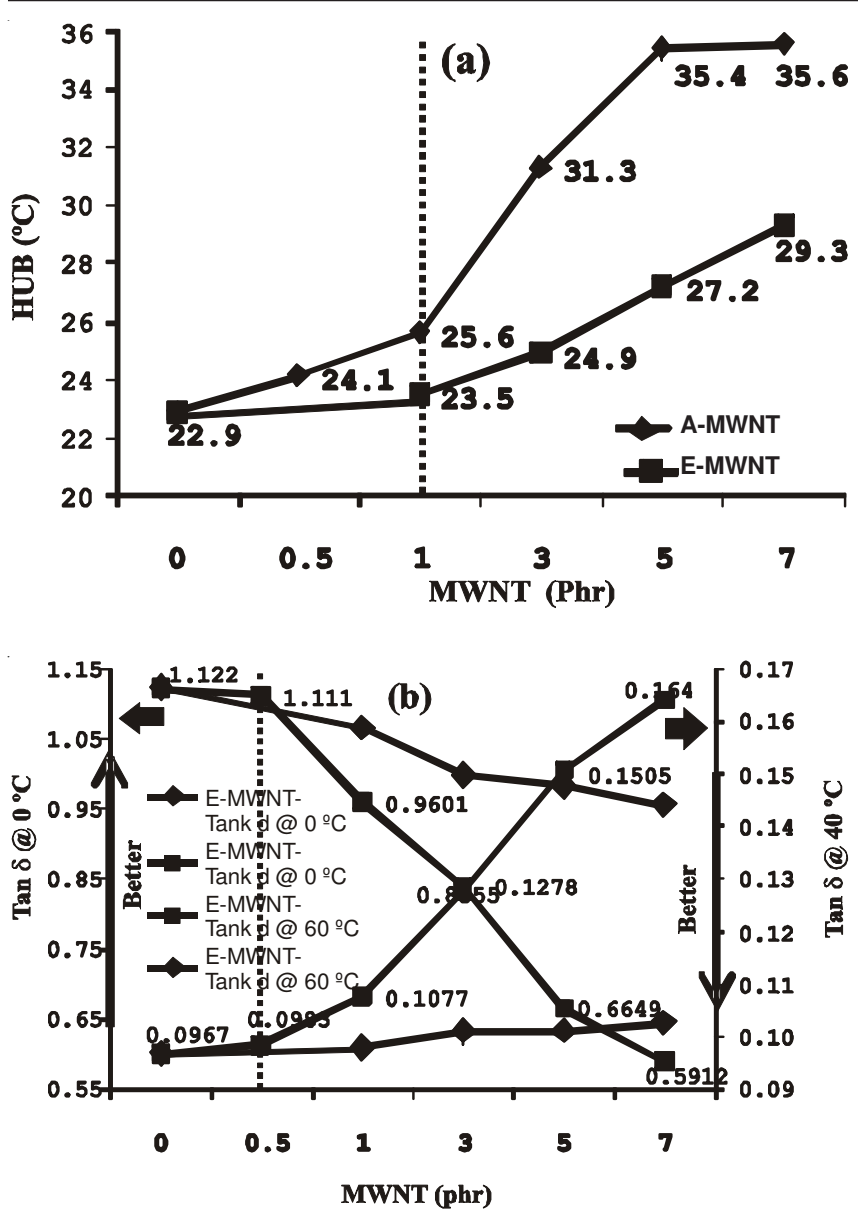

Fig. 3. Hysteresis properties of the MWNT nanocomposites ; (a) HBU and (b) Tan $\delta$ at $0{ }^{\circ} \mathrm{C}$ and $60{ }^{\circ} \mathrm{C}$

without MWNTs due to high anisotropy and well aligned long bundle structures of A-MWNT aggregates, which make it easy to abut or contact each other to form a conducting network. At a critical volume fraction (the percolation threshold), conducting paths and interconnecting filler networks form leading to a sharp decrease in the electrical resistance. Interconnecting filler networks are not formed below the critical volume fraction of carbon nanomaterials, which result in a large increase in the electrical resistance of the nanocomposites. The percolation threshold was $0.5 \mathrm{phr}$ for A-MWNT and $5 \mathrm{phr}$ for E-MWNT,

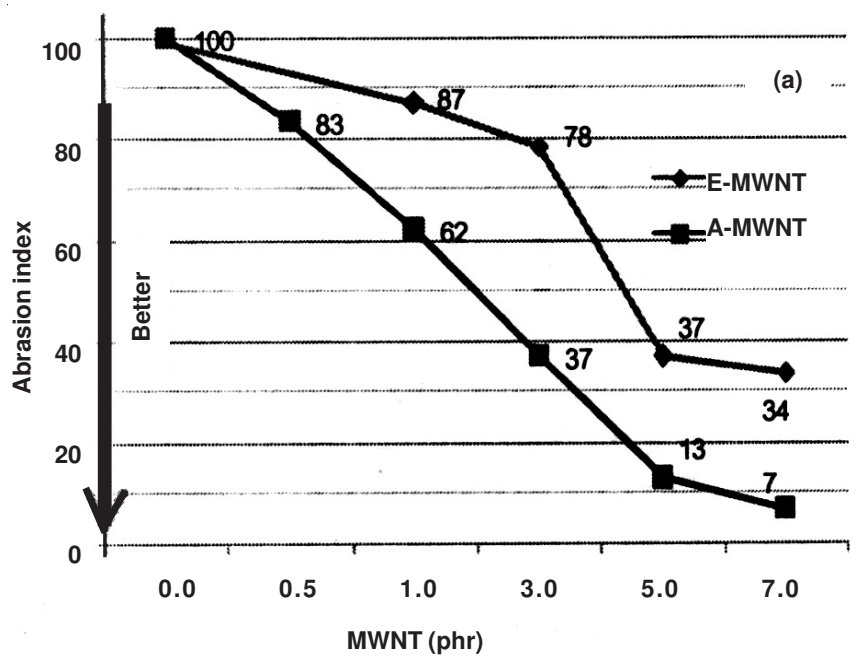

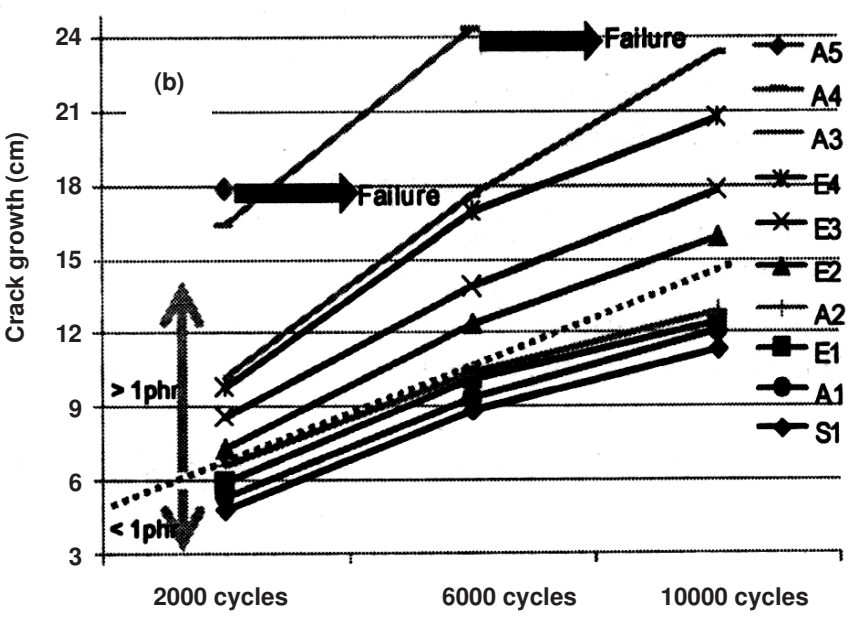

Fig. 4. Abrasion and fatigue properties of the MWNT nanocomposites; (a) abrasion index and (b) crack growth
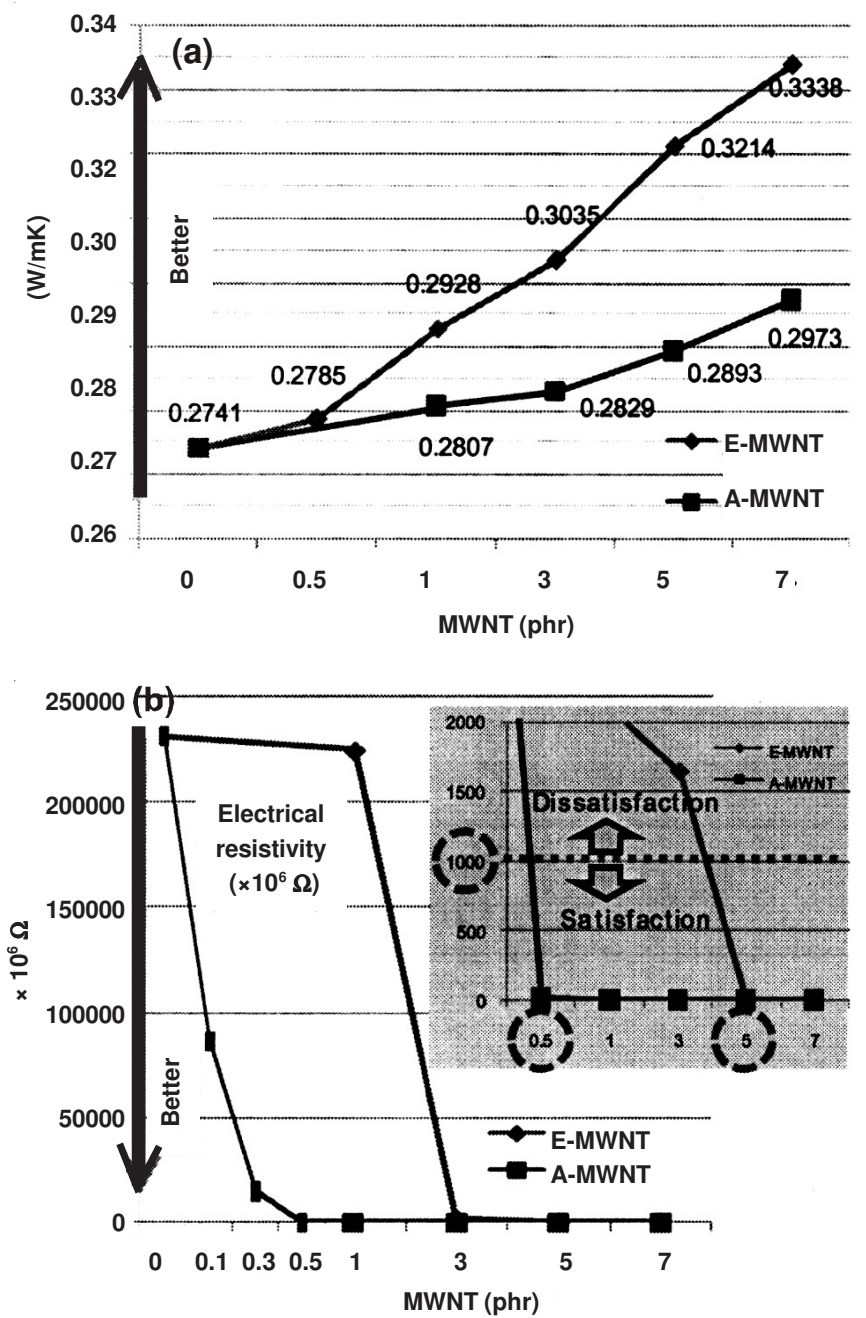

Fig. 5. Thermal and electrical properties of the MWNT nanocomposites ; (a) thermal conductivity and (b) electrical resistivity

as shown in Fig. 5. In other words, even at a low A-MWNT loading of $0.5 \mathrm{phr}$, A-MWNT enabled high silica rubber composites to obtain satisfactory static dissipation properties to the level that could meet the requirements of below $10^{8} \Omega$, whereas E-MWNT showed dissatisfactory electrical conductivity up to 5 phr due to structural disadvantages such as short 
length, entangled carbon nanotube chains and irregular spherical types of E-MWNT aggregates.

\section{Conclusion}

Styrene-butadiene rubber/natural rubber composites, which contain carbon black as a general filler and multi-wall carbon nanotube as specific fillers, were fabricated and their mechanical, fatigue, electrical, thermal and viscoelastic properties were evaluated.

A viable solution was developed for applications of tire tread compounds with high silica loadings that require high conductivity combined with good mechanical properties.

The extremely low loadings $(\sim 0.5 \mathrm{phr})$ of long aligned multi-wall carbon nanotube, which has a long length $(<120$ $\mu \mathrm{m})$ and aligned bundle structures of their aggregates, can also meet the static dissipation requirements with no measurable adverse change in the original tread compound properties, such as tensile, fatigue, heat generation, wet grip and rolling resistance. Moreover, the abrasion resistance was enhanced considerably by more than $15 \%$.

\section{REFERENCES}

1. S. Iijima, Nature, 354, 56 (1991).

2. O. Chauvet, J.M. Benoit and B. Corraze, Carbon, 42, 949 (2004).

3. J.Z. Liu, Q.S. Zheng, L.F. Wang and Q. Jiang, J. Mech. Phys. Solids, 53, 123 (2005).

4. C.Q. Sun, H.L. Bai, B.K. Tay and E.Y. Jiang, J. Phys. Chem. B, 107, 7544 (2003).

5. N. Mingo and D.A. Broido, Nano Lett., 5, 1221 (2005).

6. F. Cataldo, O. Ursini and G. Angelini, Fullerenes, Nanotubes Carbon Nanostructures, 17, 38 (2009).

7. M.S.P. Shaffer, X. Fan and A.H. Windle, Carbon, 36, 1603 (1998).

8. L. Cai, J.L. Bahr, Y. Yao and J.M. Tour, Chem. Mater, 14, 4235 (2002).

9. E.T. Mickelson, C.B. Huffman, A.G. Rinzler, R.E. Smalley, R.H. Hauge and J.L. Margrave, Chem. Phys. Lett., 296, 188 (1998).

10. J.L. Bahr, J. Yang, D.V. Kosynkin, M.J. Bronikowski, R.E. Smalley and J.M. Tour, J. Am. Chem. Soc., 123, 6536 (2001). 